\title{
O deficiente auditivo e o mercado de trabalho
}

\section{Deaf people and the labour market}

\author{
LUCIANA BORGES ${ }^{1}$, RAFAELLA BELLO ${ }^{1}$, SARAH LEITE ${ }^{1}$ \\ ROBERTO PAULO CORREIA DE ARAÚJO - Orientador ${ }^{2}$
}

${ }^{1}$ Acadêmica de Fonoaudiologia. Instituto de Ciências da Saúde da Saúde. UFBA

${ }^{2}$ Professor de Metodologia da Pesquisa Aplicada à Fonoaudiologia. Instituto de Ciências da Saúde. UFBA

\section{Resumo}

Mais recentemente, tem-se constatado, na Cidade de Salvador, que os deficientes auditivos vêm conquistando espaço no mercado de trabalho. Questiona-se, então, que motivo levou estas empresas a contratar deficientes auditivos e em que medida estes deficientes têm-se revelado eficientes? Com o intuito de responder a estas questões, foram entrevistados gerentes e supervisores de cinco empresas nas quais encontram-se surdos trabalhando. Houve diferenças nas respostas, quanto ao motivo das contratações, entre os gerentes e os supervisores. A visão da maioria dos gerentes é mais capitalista, ou seja, é a visão dos benefícios que essas contratações podem trazer para tais empresas com relação ao lucro. Já para a maioria dos supervisores, essas contratações foram feitas para ajudá-los, gerando empregos. Com relação à eficiência do trabalho dos deficientes auditivos, as respostas foram similares. A maioria considerou a eficiência dos surdos igual ou melhor do que a dos colegas ouvintes. Observa-se, então, que o trabalhador surdo tem demonstrado, cada vez mais, competência no trabalho que exerce, e que cabe às empresas abrirem espaço para essas pessoas mostrarem do que são capazes.

\section{Palavras-chave}

Emprego, deficiente auditivo, eficiência

Prof. Roberto Paulo Correia de Araújo

Departamento de Fonoaudiologia

Instituto de Ciências da Saúde

Universidade Federal da Bahia

Av. Reitor Miguel Calmon s/n Vale do Canela

40.110-100 Salvador, Bahia, Brasil

e-mail: rpcaraujo@hotmail.com / rpca@ufba.br 


\section{Introdução}

No passado, os individuos que apresentavam deficiências auditivas tinham grande dificuldade para ingressar no mercado de trabalho. Isso era conseqüência da falta de preparo tanto das empresas quanto dos surdos (SASSAKI, 1997). Atualmente, uma visão mais integrada em relação ao deficiente auditivo tem substituido os velhos discursos que enfocavam somente aspectos patológicos; considera-se o indivíduo surdo em todas as suas dimensões, e isto inclui o âmbito social em que o trabalho está inserido (KLEIN, 1998).

O trabalho tem sido, então, um meio de os surdos superarem sua deficiência e conquistarem sua autonomia, já que é um meio de sua integração à sociedade (Revista Feneis citada por KLEIN, 1998). Além disso, o trabalho é uma fonte de honra, dignidade e possibilidade de exercício da cidadania (FREEMAN; CARBIM; BOESE, 1999).

Segundo Assis, Pussoli e Lacerda (1994), o Brasil é um dos países mais avançados do mundo na criação de leis de proteção à pessoa portadora de deficiência. A lei que obriga empresas privadas a contratar deficientes auditivos é a mais conhecida. Trata-se da Lei n.o 8.123, de 25 de julho de 1991, também conhecida como Lei de reserva de mercado, em que consta:

Art. 93 - A empresa com 100 (cem) ou mais empregados está obrigada a preencher de $2 \%$ (dois por cento) a $5 \%$ (cinco por cento) dos seus cargos com beneficiários reabilitados ou Pessoa Portadora de Deficiência, habilitados, na seguinte proporção:

$$
\begin{aligned}
& 1 \text { - até } 200 \text { empregados...... 2\% } \\
& 2 \text { - de } 201 \text { a } 500 \ldots \ldots \ldots \ldots \ldots . . . . .3 \% \\
& 3 \text { - de } 501 \text { a } 1000 \ldots \ldots \ldots \ldots . . . . .4 \% \\
& 4 \text { - de } 1001 \text { em diante......... 5\% } \\
& \text { (apud ASSIS; PUSSOLI; LACERDA, 1994, p. 56) }
\end{aligned}
$$

Há também essa obrigação de inclusão do deficiente auditivo no setor público, conforme consta na Constituição Federal de 1988:

Art. 37, VIII: A lei preservará percentual de cargos e empregos públicos para as Pessoas Portadoras de Deficiência e definirá os critérios de sua admissão (apud ASSIS; PUSSOLI, LACERDA, 1994, p. 57)

Porém, para Carreira (1997), apesar de existirem tantas leis, muitos empresários ainda desconhecem a capacidade de trabalho do surdo e as medidas administrativas para sua contratação (recrutamento, seleção, treinamento, legislação). Mesmo assim, já não é difícil ver, com freqüência, na Cidade do Salvador, surdos trabalhando em supermercados ou hotéis. Que razão têm tido essas empresas para procurar conhecer melhor o universo do deficiente auditivo? Gentili (citado por KLEIN, 1998) acredita que o neoliberalismo vivido atualmente colabora para uma valorização das competências individuais.

O que se quer dizer com isso é que, se o Estado deixa de atuar na economia tão diretamente, as empresas, por sua vez, ganham autonomia e se lançam em mercados externos, assim como as de outros países entram no mercado brasileiro. Há, portanto, uma guerra de qualidade para poder sobreviver; já não se pode ser apenas "bom"; busca-se, agora, o titulo de "excelente". Conseqüentemente, abandona-se qualquer idéia pré-estabelecida de funcionário e procura-se por qualquer pessoa que desempenhe determinada tarefa de forma excelente, o melhor.

Vindo somar-se a essa tendência econômica, tem-se também o fato de que, a partir das décadas de 60/70, "a teoria do capital humano colocou de forma precisa e unidirecional a relação entre educação e desenvolvimento econômico" (GENTILI citado por KLEIN, 1998, p. 84), ou seja, surgiu a idéia de que bastava conhecimento (educação) para se ascender a um lugar de trabalho, independentemente de cor, sexo ou condição física.

Era necessário, então, que se equipasse o deficiente auditivo com o conhecimento para exercer sua profissão. Nesse sentido, instituições e escolas especiais vêm trabalhando para oferecer ao surdo os instrumentos necessários para se tornarem trabalhadores. Klein (1998) afirma que esse processo de formação, por parte das escolas especiais, não se resume à aquisição de conhecimentos considerados úteis e necessários ao exercício de uma profissão, mas atua diretamente no que se refere a um disciplinamento do sujeito para uma melhor adequação às necessidades do mundo do trabalho, ou seja, há também uma preocu- 
pação com todo o lado comportamental socialmente aceito, mesmo porque cada atividade profissional exige um perfil específico do seu ocupante. Na concretização desse processo, participam vários profissionais: assistentes sociais, psicólogos e orientadores educacionais, que fazem desde a orientação profissional até o encaminhamento para o emprego.

Voltando à questão da razão pela qual empresas têm contratado deficientes auditivos, Mader (1998) considera que há uma tendência atual de se julgar a diferença como algo inerente aos seres humanos, havendo, portanto, uma valorização da diversidade. "O conceito de dualidade que fundamenta a separação entre corpo e alma, preto e branco, matéria e energia, natureza e cultura começa a dar espaço a uma visão mais integrada, holística" (KUHN citado por MADER, 1998, p. 48). Apesar de se estar vivendo num tempo de capitalismo exacerbado, algumas empresas podem estar admitindo deficientes auditivos com base no ideal socialista, concordando total ou parcialmente com suas propostas. "Os socialistas são rigorosamente contra qualquer forma de discriminação e desigualdade social. Têm como objetivo uma sociedade baseada na cooperação e fraternidade, em vez de competição e interesse pessoal" (ENCICLOPÉDIA DELTA UNIVERSAL, 1980, p. 7359). O presente trabalho não descarta, portanto, a idéia de se estar vivendo uma retomada de antigos valores. Os empresários podem realmente estar despertando para a necessidade de reconhecer no surdo um ser humano, com potencialidades a serem desenvolvidas e, acima de tudo, alguém que merece igualdade de condições para ser um cidadão ativo da sociedade. Assim sendo, podem-se encontrar empresas que tenham a consciência de sua responsabilidade na inserção do deficiente auditivo no meio social.

Nessa atmosfera de transformações é que muitas empresas, junto com escolas especiais e instituições, têm-se lançado no compromisso de inclusão do deficiente auditivo, iniciando um processo sobre o qual há ainda muito a se conhecer e aprimorar. Resta saber se todo esse esforço tem produzido o esperado. No presente trabalho, pretende-se, portanto, identificar as razões que levaram as cinco empresas selecionadas a contratar deficientes auditivos e comparar sua eficiência em relação à de seus colegas ouvintes.

\section{Materiais e métodos}

A pesquisa se desenvolveu junto a cinco empresas: Catussaba Hotel (EMP I), Bahia Othon Palace (EMP II), Surpresa Supermercados (EMP III), Masani Supermercados (EMP IV), Nunes Calçados (EMP V) indicadas pela Associação de Pais e Amigos do Deficiente Auditivo (APADA), todas elas empresas de médio porte e de fácil acesso.

Os dados foram colhidos através de questionário aplicado aos supervisores e gerentes, indivíduos diretamente responsáveis pelos setores em que trabalham os deficientes auditivos.

\section{Resultados e discussão}

Todas as empresas visitadas passaram a contar com deficientes auditivos em seus estabelecimentos há menos de três anos, confirmando a já referida suspeita de que se trata de uma "novidade" em Salvador. As razões que levaram ao processo de admissão de deficientes auditivos decorrem de dois pontos de vista diferentes: o primeiro é o de um funcionário com função superior na empresa, atuando na gerência; o segundo é o de outro funcionário que lida diretamente com o surdo e é supervisor.

Conforme pode ser observado no QUADRO 1, entre os gerentes das empresas, quando questionados acerca das razões que os levaram a contratar deficientes auditivos, $40 \%$ afirmam que o fizeram pela obrigação imposta pela Lei $n^{\circ}$ 8.123, art. 93; é importante frisar que, de acordo com a lei, somente essas duas empresas, entre as cinco entrevistadas, são obrigadas a contratar deficientes auditivos, por possuírem mais de 100 (cem) funcionários em seu quadro; outros $40 \%$ revelaram que se beneficiam, aceitando os deficientes auditivos pelo fato de o custo ser menor, já que eles são prestadores de serviços e, portanto, não têm vínculo empregatício; e os $20 \%$ restantes os contrataram porque queriam fazer novas experiências. 
Já entre os supervisores, $40 \%$ acreditam que a empresa passou a admitir deficientes auditivos porque desejou ajudá-los, gerando empregos; outros $40 \%$ disseram que acreditam ser os deficientes de menor custo para a empresa (apesar de esta não ser uma realidade dentro dessas empresas, pois os deficientes trabalhavam com carteira assinada e, portanto, tinham salário igual aos dos outros funcionários de mesma função, além de férias, $13^{\circ}$ salário, etc.); e os $20 \%$ restantes acreditam que a empresa queria fazer novas experiências.

Preliminarmente, foram levantadas três hipóteses para explicar a razão pela qual empresas de Salvador estariam abrindo espaço para o trabalho dos deficientes auditivos, a saber: o neoliberalismo econômico que é fruto do pensamento capitalista, a visão holística, segundo a qual elementos diferentes se completam e, por fim, a consciência de sua responsabilidade social, dando ao deficiente a possibilidade de mostrar sua "força".

\section{QUADRO 1}

Razões que levaram a empresa a contratar deficientes auditivos

\begin{tabular}{lll}
\hline EMPRESA & GERENTE & SUPERVISOR \\
\hline EMP I & Lei de reserva de mercado & Custo menor \\
EMP II & Lei de reserva de mercado & Custo menor \\
EMP III & Custo menor & Gerar empregos \\
EMP IV & Custo menor & Gerar empregos \\
EMP V & Novas experiências & Novas experiências \\
\hline
\end{tabular}

Fonte - Pesquisa de campo, 2000.

Após a análise dos resultados, constatouse que o pensamento neoliberal é mais pronunciado nas respostas dos gerentes. As razões mais mencionadas por eles como motivo de destinação de vagas em suas empresas para deficientes auditivos foram: a lei de reserva de mercado e o menor custo para a empresa, que serão discutidas a seguir. O Brasil, segundo Assis, Pussoli e Lacerda (1994), é um dos países mais avançados na criação de leis de proteção à pessoa portadora de deficiência. Há inúmeras leis que asseguram, aos deficientes auditivos, acesso ao trabalho, igualdade de condições e salários, etc., tanto no setor privado, como no público, como já foi mostrado. Com isto, verifica-se uma posi- ção de caráter paternalista do Estado, no intuito de prover ao surdo elementos básicos para se tornar um cidadão. Porém, o enfoque da presente pesquisa é a visão dos empresários, e estes, em parcela significativa (40\%), afirmam tê-los contratado por mera obrigação, para não estar infringindo a lei. É importante comentar que, embora haja muitas leis de proteção aos deficientes, não significa que elas sejam eficazes. Então, se não há um cumprimento efetivo dessas leis, essas empresas poderiam perfeitamente ignorá-las; o que acontece é que, ao ter contato com o trabalho dos deficientes, verificaram tratar-se de um serviço de maior qualidade e, portanto, de maior proveito para a empresa. A lei foi, então, apenas um meio para que se conhecesse o trabalho dos deficientes, e estes, por si, garantiram sua manutenção nesses cargos.

Outra razão citada pelos gerentes que teve valor significativo (40\%) foi o fato de a mão-deobra do deficiente ser mais barata. Nesses estabelecimentos, os surdos não tinham contrato de carteira assinada, eram prestadores de serviços. Não se pôde comparar a questão do salário por serem os surdos os únicos a desempenharem essa função. Nessas empresas, pôde-se verificar que os gerentes consideram o trabalho do surdo melhor do que o de ouvintes que já desempenharam a mesma função, como será discutido posteriormente. $\mathrm{O}$ que se constata, então, é que se se tem um serviço de melhor qualidade por um preço menor, melhor será a relação custo $\mathrm{x}$ benefício da empresa. Isto é o fundamento do modelo econômico vivenciado atualmente, em que se tira o máximo do empregado, ficando a empresa isenta de maiores gastos, não se preocupando se há nisso justiça ou não. Carreira (1997), seguindo essa mesma linha de raciocínio, afirma que os setores da sociedade devem entender que uma pessoa improdutiva pesa, em termos de impostos, muito mais do que se ela estiver inserida no mercado de trabalho.

Quanto à análise das respostas dos supervisores, convém ressaltar a limitação do grau de instrução e o fato de trabalharem fisicamente mais próximos dos deficientes, o que assegura maior intimidade com eles. Essa aproximação pôde ser 
sentida pelos resultados da pesquisa. Uma parcela significativa (40\%) acha que a empresa admitiu surdos porque tinha interesse em gerar empregos e, mais do que isso, queria ajudar o deficiente. Esta é uma posição extremamente humanitária e solidária e contrapõe-se à visão dos gerentes que visam primordialmente ao lucro da empresa. Outros $40 \%$ responderam que o fato de o surdo ter menor custo levou sua empresa a contratá-los, mas esta não é uma realidade dentro dessas empresas, já que os surdos têm carteira assinada, o que demonstra o desconhecimento desses supervisores.

Outro ponto importante da pesquisa foi saber se havia diferenças entre o trabalho do surdo e o trabalho do ouvinte ao desempenharem a mesma função. Com relação ao item rapidez, 40\% das empresas consideram o deficiente auditivo melhor, enquanto $60 \%$ afirmam não haver diferenças; já em relação à concentração, 60\% acreditam que o surdo tem melhor desempenho, contra 40\% que não vêem diferenças; da mesma maneira, $60 \%$ creditam ao deficiente maior produtividade, enquanto $40 \%$ consideram que surdos e ouvintes têm-na do mesmo modo.

Para 20\% das empresas, o deficiente auditivo está em desvantagem no quesito compreensão de ordens, por conta da dificuldade que tem em compreender o que se lhe é dito. No tocante a esta matéria, nada é feito para minimizar o problema, visto que se trata de uma desvantagem inerente à deficiência auditiva. Foi solicitado aos entrevistados que apontassem qualquer outra diferença entre o trabalho dos surdos e dos ouvintes e constatou-se que $40 \%$ consideram o deficiente auditivo mais detalhista e com mais iniciativa, tornando seu trabalho, para essas funções, de melhor qualidade. Em 100\% das empresas investigadas, constatou-se que não há preparação dos funcionários ouvintes que desempenham a mesma função, ou dos chefes para atuar junto ao surdo, muito embora a APADA tenha efetuado reuniões em $40 \%$ dessas empresas, a fim de comunicar a integração ao quadro funcional de deficientes auditivos.

Com relação à função exercida pelo deficiente auditivo nas empresas entrevistadas, constata-se que, em 40\% delas, eles realizam a função de empacotadores; em outros $40 \%$, eles são funcionários de limpeza e apenas em 20\% sua atividade é de conferência de cartões de crédito. $\mathrm{Na}$ grande maioria das vezes, não se exige que o surdo saiba ler ou escrever (empacotadores ou funcionários de limpeza), o que leva à conclusão de que eles ainda exercem atividades que requerem mais força física do que intelecto. Isso também evidencia a necessidade de melhor formação educacional para que o surdo tenha um número maior de opções de trabalho e tenha, ao menos, a chance de mostrar suas habilidades, como tem feito até agora. Em 80\% das empresas, os deficientes auditivos têm contato com o público que consensualmente demonstra aprovação pelo trabalho desenvolvido por estes individuos. De um modo geral, o público demonstra estar satisfeito, muito embora em diversas oportunidades expresse dificuldade em compreender o que o deficiente auditivo the comunica.

Nas empresas avaliadas, não se esperava encontrar grandes dificuldades de integração de funcionários surdos, visto que todas foram indicadas pela APADA. O que se quer dizer com isto é que os deficientes auditivos tiveram uma preparação anterior ao trabalho. Na APADA, uma equipe de pedagogos, psicólogos e assistentes sociais ensinam ao deficiente auditivo desde condutas sociais até o ofício que desempenharão posteriormente. Por isso é que o treinamento é específico para cada empresa para a qual serão encaminhados. Depois, a APADA acompanha seu aluno por um período de três meses de treinamento na empresa, com um intérprete, inclusive, e, após esse periodo, a APADA continua a ser a intermediária entre o surdo e a empresa, sendo solicitada sempre que necessário.

\section{Conclusões}

A principal questão da presente pesquisa foi saber por que empresas de Salvador estariam contratando deficientes auditivos. A explicação para este fato vem da competência que o trabalhador surdo tem demonstrado cada vez mais. 
Mesmo assim, alguns fatores foram necessários para que se tomasse conhecimento desse valor. Os dois fatores mais mencionados foram a Lei de reserva de mercado e o menor custo com o surdo quando não tem vínculo empregatício. De qualquer sorte, qualquer desses fatores, sem a competência do surdo, não seria suficiente para sua permanência na empresa.

Conforme já era esperado, as empresas, nesse momento de capitalismo exagerado, optam pela maior qualidade e absoluto controle de gastos. $O$ deficiente auditivo, assim como outras classes de minoria, deve aproveitar o momento para mostrar o que sabe fazer de forma excelente, garantindo seu lugar no mercado de trabalho e, conseqüentemente, sua possibilidade de ser ci- dadão atuante na sociedade. Aos fonoaudiólogos, cabe reconhecer este momento e atuar na capacitação do deficiente auditivo para propiciarlhe melhor comunicação, que é como se constroem as relações sociais. Sugere-se, então, que se criem mecanismos para fazer cumprir a lei, o que proporcionará a muitas empresas tomar conhecimento de habilidades distintas das que elas já conhecem, que em muito podem aumentar sua produtividade e eficiência.

\section{Agradecimentos}

À Prof ${ }^{\mathrm{a}}$ Ana Paula Corona, pela especial atenção dispensada quando da formulação de consultas acadêmicas na área de Fonoaudiologia.

\begin{abstract}
Nowadays, there is increasing evidence that many companies in Salvador have been hiring deaf people. That evidence raises some questions: why are those businessmen contracting them and how efficient are deaf people? In order to answer those questions, we interviewed five managers and five supervisors who work in companies where deaf people work together with normal employees, in charge of the same procedures. There were differences between the managers' and the supervisors' answers as far as the reasons for the contracts were concerned. The majority of the managers have a capitalist point of view so most of them said that their companies had contracted deaf people because it increased the company's profit or because the company was obliged to do it by the force of the law. On the other hand, most of the supervisors think that the companies have hired deaf people with the intention of giving them the opportunity for getting a job. As for their efficiency, most of the interviewed people considered the deaf people equal or better than the normal ones when doing the same tasks. Deaf people have been showing the society their competence for work. It is expected that the businessmen realize the deaf people's importance and give them the opportunity to prove how capable they are.
\end{abstract}

\title{
Key words
}

Job, deaf people, efficiency

\section{Referências}

ASSIS, Oliney Queiroz; PUSSOLI, Lafaiete; LACERDA, Vanderley Andrade de. Os direitos da pessoa portadora de deficiência. São Paulo: Lúmen, 1994. p. 56-69.

CARREIRA, Dorival. A integração da pessoa deficiente no mercado de trabalho. In: MANTOAN, Maria Teresa Eglés et al. (Org.) A integração de pessoas com deficiência: contribuições para uma reflexão sobre o tema. São Paulo: Memnon, 1997. p. 24-31.

FREEMAN, Roger; CARBIM, Clifton; BOESE, Robert J. Seu filho não escuta? Um guia para todos os que lidam com crianças surdas. Santos: Brasilia, 1999.

KLEIN, Madalena. Os discursos sobre surdez, trabalho e educação e a formação do surdo trabalhador. In: SKLIAR,
Carlos (Org.). A surdez: um olhar sobre as diferenças. Porto Alegre: Meditação, 1998. p. 75-91.

MADER, Gabriele. Integração da pessoa portadora de deficiência: a vivência de um novo paradigma. In: MANTOAN, Maria Teresa Eglés et al. (Org.) A integração de pessoas com deficiência: contribuições para uma reflexão sobre o tema. São Paulo: Memnon, 1997. p. 44-50.

SASSAKI, Romeu Kazumi. Inclusão: construindo uma sociedade para todos. 3. ed. Rio de Janeiro: WVA, 1999. p. 59-83 e 145-152.

SOCIALISMO. In: ENCICLOPÉDIA Delta Universal. Rio de Janeiro: Delta, 1980. p. 7539. 